\title{
Pregnancy-related listeriosis in France, 1984 to 2011, with a focus on 606 cases from 1999 to 2011
}

D Girard (delphine.gd@gmail.com)1 ${ }^{1}$, A Leclercq ${ }^{2,3}$, E Laurent ${ }^{1}$, M Lecuit $^{2,3,4,5}$, H de Valk ${ }^{1}$, V Goulet $^{1}$

1. Institut de Veille Sanitaire, Saint-Maurice, France

2. Institut Pasteur, National Reference Centre and World Health Organisation Collaborating Centre for Listeria, Paris, France

3. Institut Pasteur, Biology of Infection Unit, Paris, France

4. Institut National de la Sante et de la Recherche Medicale, Inserm U1117, Paris, France

5. Paris Descartes University, Necker-Enfants malades University Hospital, Division of Infectious Diseases and Tropical Medicine, Paris, France

Citation style for this article:

Girard D, Leclercq A, Laurent E, Lecuit M, de Valk H, Goulet V. Pregnancy-related listeriosis in France, 1984 to 2011 , with a focus on 606 cases from 1999 to 2011. Euro Surveill. 2014;19(38):pii=20909. Available online: http://www.eurosurveillance.org/ViewArticle.aspx?Articleld=20909

Article submitted on 17 October 2013 / published on 11 September 2014

This study describes trends in the incidence of pregnancy-related listeriosis in France between 1984 and 2011, and presents the major characteristics of 606 cases reported between 1999 and 2011 to the French Institute for Public Health Surveillance through the mandatory notification system. The incidence of pregnancy-related listeriosis decreased by a factor of 12 from 1984 to 2011. This reduction was a result of progressive implementation of specific Listeria monocytogenes control measures in food production. A lower incidence of pregnancy-related listeriosis was observed in regions with a lower prevalence of toxoplasmosis. Given that dietary recommendations in pregnancy target both toxoplasmosis and listeriosis prevention, we suppose that recommendations may have been delivered and followed more frequently in these regions. Cases reported between 1999 and 2011 $(n=606)$ were classified as maternal infections with ongoing pregnancy $(n=89,15 \%)$, fetal loss $(n=166$, $27 \%$ ), or live-born neonatal listeriosis $(n=351,58 \%)$. The majority of live-born neonatal listeriosis cases $(n=216,64 \%)$ were preterm births (22-36 weeks of gestation), of whom $14 \%(n=30)$ were extremely preterm births (22-27 weeks of gestation). Eighty per cent of mothers reported having eaten high risk food during pregnancy. A better awareness of dietary recommendations in pregnant women is therefore necessary.

\section{Introduction}

Invasive listeriosis is a rare but severe infection caused by Listeria monocytogenes, a bacterium capable of growing at low temperatures but destroyed by heat. Human listeriosis is mainly transmitted by food $[1,2]$ and generally affects immunocompromised individuals, pregnant women and newborns [3]. The symptoms of listeriosis in pregnant women are non-specific and often include an influenza-like syndrome. The main risk associated with listeriosis during pregnancy is haematogenous transmission to the fetus through the placenta. Listeriosis can develop at any time during pregnancy [4] and can result in fetal loss, preterm birth and/or neonatal infection [5]. Transmission to the fetus can also occur through ingestion of amniotic fluid [6]. Nosocomial transmission is occasionally reported in maternity units $[7,8]$. The proportion of pregnancyrelated listeriosis decreased strongly between the 1980 s and 1997 , from nearly $50 \%$ to less than $25 \%$ of all invasive listeriosis cases [9]. The objectives of this study were to describe trends in the incidence of pregnancy-related listeriosis in France between 1984 and 2011, and the major characteristics of the 606 cases recorded between 1999 and 2011.

\section{Methods}

\section{Data sources}

The main indicator used to describe the annual incidence of pregnancy-related listeriosis is the rate of number of cases per number of live births in the French population. The number of live births is recorded every year by the French Statistical Office (Institut National de la Statistique et des Etudes Economiques; INSEE) [10]. The number of cases was retrieved from different sources for the following periods:

- 1984-1991: studies by the French National Health Laboratory [9,11].

- 1992-1998: National Listeria Reference Centre (NLRC) database. NLRC started ascertaining cases nationwide in 1992 because of a listeriosis outbreak [12]. The number of cases related to that outbreak has not been considered for the calculation of the annual incidence rate. In 1997 , the sensitivity estimation of case ascertainment was $76 \%$ [9].

- 1999-2011: mandatory notifications. Listeriosis has been listed for mandatory notification in France since 1999. Accordingly, each diagnosed case must be declared by clinicians and laboratories to the regional health agency. Sensitivity was estimated at $87 \%$ in 2001 [13] and at 92\% in 2006 (data not shown), using the capture-recapture method. The mandatory notification includes demographic, clinical, and laboratory 
information [14]. Moreover, upon diagnosis, mothers are asked to complete a standard food questionnaire on their eating habits in the past two months. After validation of the content, the mandatory notifications and the food questionnaires are sent by the regional health agencies to the French Institute for Public Health Surveillance (InVS).

The annual incidence rate was estimated from 1984 to 2011, considering the sensitivity of each data source.

\section{Case definition}

In France, the diagnosis of listeriosis is made when $L$. monocytogenes is isolated from a normally sterile site in a patient presenting symptoms clinically compatible with listeriosis. A case is considered pregnancy-related when it involves a pregnant woman, a miscarriage, a stillbirth, or a newborn less than 28 days-old. When L. monocytogenes is isolated from both the pregnant women and her newborn child, this is counted as a single case. Gestational age is given by the number of weeks of amenorrhoea. According to the information on the mandatory notification form, we categorised each case as ongoing pregnancy (diagnosis of invasive listeriosis in a pregnant woman with no concomitant delivery), fetal loss (miscarriage if gestational age is less than 22 weeks of gestation (WG), stillbirth if it is at least 22 WG), or live-born neonatal listeriosis (L. monocytogenes infection diagnosed in a newborn before 28 days of age). Live-born neonatal listeriosis was subclassified as 'early neonatal cases' (diagnosed between birth and day 6) or 'late neonatal cases' (diagnosed between day 7 and day 28). Early neonatal cases were classified as confirmed cases (L. monocytogenes isolated in the neonate's cerebrospinal fluid (CSF) or the neonate's blood), probable cases (L. monocytogenes isolated from placenta, the mother's blood, or the neonate's gastric aspirate), or possible cases (positive swab(s) from the neonate's surface sites). Finally, neonatal listeriosis was defined as an infection of the newborn [ $\geq 22$ WG independent of its vital status, i.e. stillbirths and live-born neonatal listeriosis].

Confirmation and characterisation of $L$. monocytogenes isolates by NLRC

Listeria isolates from pregnancy-related listeriosis referred to NLRC were confirmed with API Listeria (API, Appareil et Procédé d'Identification, bioMérieux, Marcy l'Etoile, France) [15] and serotyped by the slide agglutination method until January 2005 [16] and by multiplex PCR [17] starting February 2005. According to our experience, the PCR groups correspond fully to the four major serovars that cause human disease. Ongoing subtyping was conducted by

\section{FIGURE 1}

Incidence of pregnancy-related listeriosis, France, 1984-2011

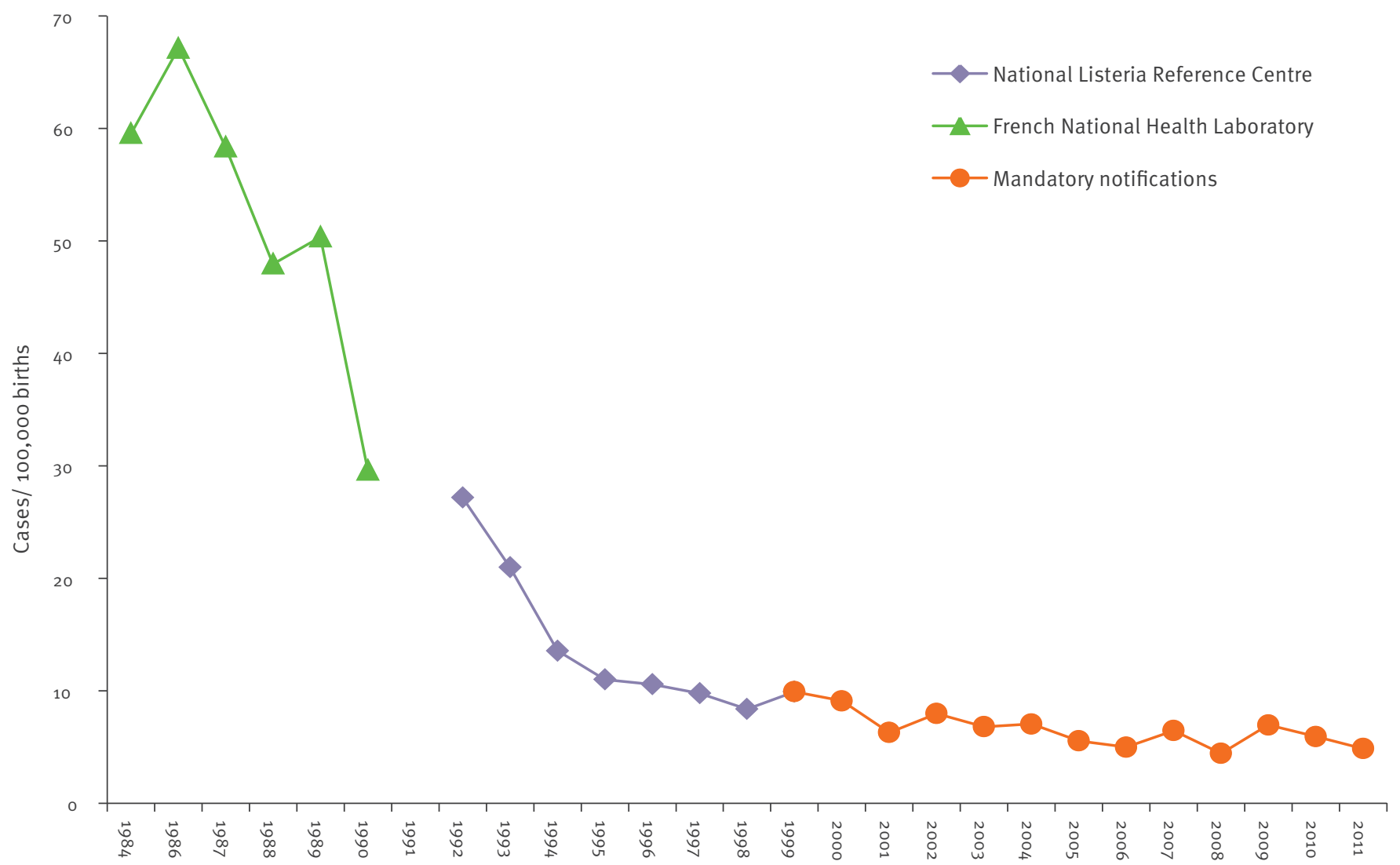

Year of onset 
DNA macrorestriction profiles analysis (pulsed-field gel electrophoresis; PFGE) according to standard protocols [18]. Isolates with indistinguishable Apal and Ascl DNA macrorestriction profiles, first based on visual comparison of banding patterns (since 2006 using BioNumerics 6.6 software; Applied Maths SaintMartens-Latem, Belgium), were considered to be the same pulsovar. Susceptibility to a panel of 23 antibiotics was determined for each strain by disk diffusion according to guidelines from the European Committee on Antimicrobial Susceptibility Testing (EUCAST) and Clinical and Laboratory Standards Institute (CLSI) [19-21].

\section{Statistical analyses}

Results are expressed as numbers and percentages for categorical variables and as mean \pm standard deviation (SD) or median (range) for continuous variables as appropriate. Associations between categorical variables were assessed using the chi-squared test or Fischer's exact test as appropriate. Associations between continuous and categorical variables were assessed using Student's t-test or Kruskal-Wallis test as appropriate. Correlation between continuous variables was assessed using Pearson's or Spearman's correlation coefficients as appropriate. Statistical analysis was performed using Stata11.

\section{Results}

\section{Incidence of pregnancy-related listeriosis}

The annual incidence rate of pregnancy-related listeriosis per 100,000 live births fell from $60(n=453)$ to 5 $(n=35)$ cases per 100,000 live births between 1984 and 2011, a decline by a factor of 12 . It decreased markedly between 1986 and 1996, gradually from 1996 to 2006 and was then stable until 2011 (Figure 1). From 1999 to 2011, the overall incidence rate of pregnancy-related listeriosis was 6.1 per 100,000 live births and varied according to the region from 2.2 to 13.6. It was highest in the Paris region and in the south-west of France (Figure 2). The incidence rate of pregnancy-related listeriosis was independent of the incidence rate of non-pregnancy-related listeriosis in all the regions of France $(r=0.16, p=0.07)$. Pregnancy-related listeriosis was more frequent from July to September than during the rest of the year (mean: $5.0 \pm 2.6$ vs $3.5 \pm 2.0$ cases per month, p<0.001). Seasonal incidence of pregnancyrelated listeriosis was not parallel to the incidence observed for non-pregnancy-related listeriosis which was higher from May to July than during the rest of the year (mean: $21.7 \pm 1.2$ vs $16.3 \pm 2.7$ cases, $p=0.008$ ) (Figure 3).

\section{Cases from 1999 to 2011}

We focused our study on the period 1999 to 2011, after the introduction of mandatory notification of listeriosis in France. A total of 3,413 cases of listeriosis were recorded from 1999 to 2011, of which 606 (18\%) were considered pregnancy-related (Table 1). The mean age of the mothers was $29.5 \pm 6.1$ years. There was

\section{FIGURE 2}

Average annual incidence rates of listeriosis, by Région, France, 1999-2011 $(\mathrm{n}=606)$

\section{A. Pregnancy-related listeriosis}

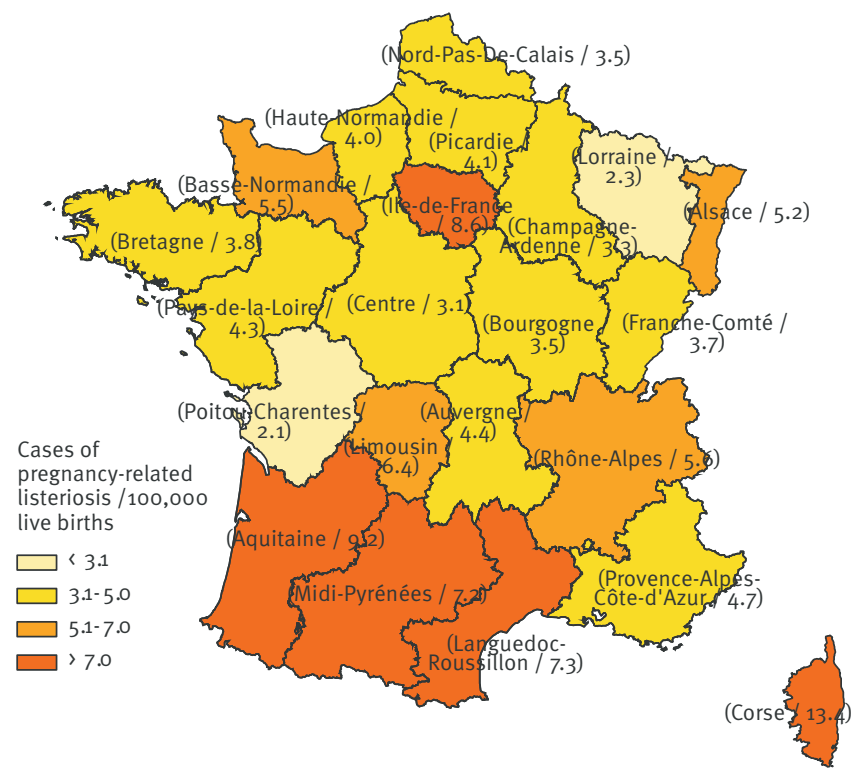

B. Non-pregnancy-related listeriosis

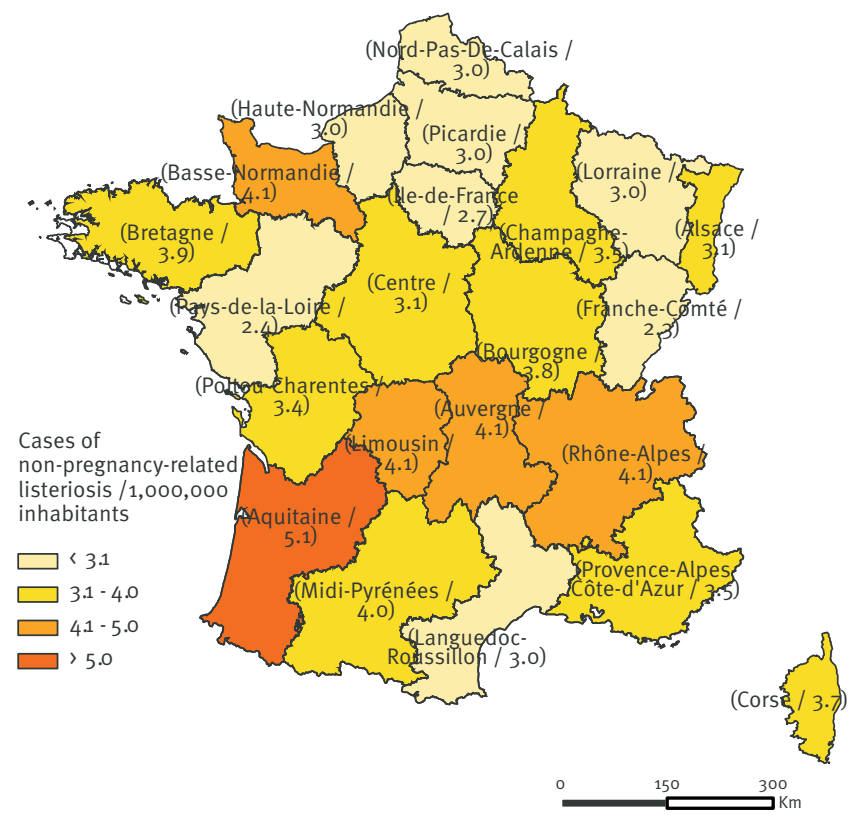

Software used to draw the map: IGN-GéoFLA, using administrative boundaries from 1999.

Data source: InVS, October 1013.

no significant difference to the mean age of mothers in the general population who gave birth in France in

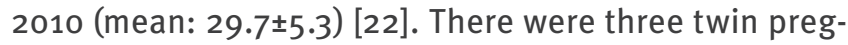
nancies which resulted in six live-born neonatal listeriosis cases.

Among the 603 mothers with pregnancy-related listeriosis notified from 1999 to 2011, 15 (3\%) were immunocompromised (eight human immunodeficiency virus (HIV)-positive including one with acquired 
Median number of listeriosis cases per month, France, 1999-2011 (n=606)

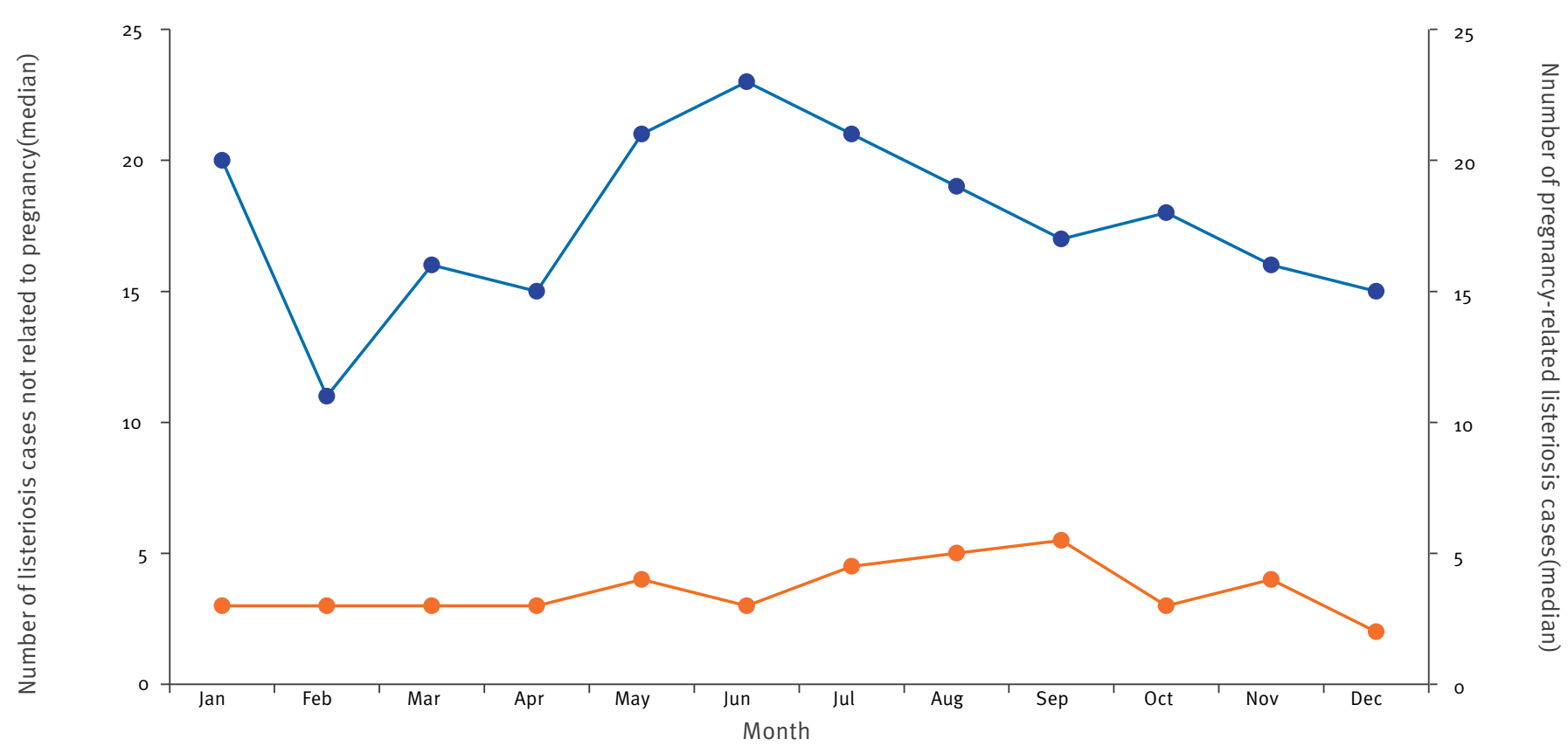

immunodeficiency syndrome (AIDS), two with rheumatoid polyarthritis, two with haemorrhagic rectocolitis, two under immunosuppressive therapy but with unknown comorbidity, and one with chronic lymphocytic leukaemia). All mothers survived. Gestational age at diagnosis was recorded for 585 cases (Table 2). The median gestation period at diagnosis was 32 weeks (range: 5-41 weeks). Maternal infection was confirmed by $L$. monocytogenes isolates in blood $(n=272,45 \%)$ and/or placenta $(n=215,35 \%)$ and/or CSF $(n=3,0.01 \%)$. Of the women with meningitis, one lost the fetus at 12 WG, the two other women gave birth to a live neonate.

Among the 603 mothers, 509 (84\%) completed the food questionnaire (Table 1). During the two months before diagnosis, $405(80 \%)$ mothers had eaten at least one high risk product not recommended during pregnancy, mainly pâté (51\%), and smoked salmon (33\%). In southwestern France, where listeriosis incidence is highest, mothers more often reported the consumption of highrisk products than in other regions, in particular of a type of pâté called rillettes ( $26 \%$ vs $16 \%$, pro.05), and Pyrénées' cheeses (20\% vs 5\%, pro.001). They also reported eating uncooked meat more frequently $(40 \%$ vs $17 \%, \mathrm{p}(0.001)$.

\section{Ongoing pregnancy}

Ongoing pregnancies were infrequent $(n=89 / 603,15 \%)$ and were diagnosed at (median) 30 WG (range: 7-39 WG). All cases were confirmed by L. monocytogenespositive blood culture. All mothers were treated with antibiotics (information on the type of antibiotic were not available to the authors) and only one of the newborns was infected with $L$. monocytogenes. Review of this case revealed that the mother had had fever at 28 WG. She was treated with cephalosporins that are ineffective against $L$. monocytogenes [23]. When the result of the blood culture was available, she had no more fever and treatment was not changed. Three weeks later, she delivered a newborn with invasive listeriosis (positive blood culture).

\section{Fetal loss}

Pregnancies resulted in 166 fetal losses (27\%). There was a median of 13 (range: 9-21) fetal losses per year. Fetal losses occurred at a median of 21 WG (range: 5-37 WG) and 90\% occurred before 28 WG (Table 2). There were $95(57 \%)$ miscarriages and $71(43 \%)$ stillbirths which occurred at a median of 18 WG (range: 5-21 WG) and 25 WG (range: 22-37 WG) respectively. Fetal loss decreased significantly with gestational age at diagnosis (p<0.001) (Table 2).

\section{Live-born neonatal listeriosis}

Live-born neonatal listeriosis accounted for $58 \%$ $(n=351)$ of pregnancy-related listeriosis and occurred at a median gestation period of 35 weeks (range to 22-41 weeks) in the 337 cases for whom gestational age was known. A majority of live-born neonates $(n=216,64 \%)$ were preterm births (i.e. 22-36 WG), of whom $14 \%$ $(n=30)$ were extremely preterm births (i.e. 22-27 WG) (Table 2).

Among the neonatal cases, 329 (94\%) were early neonatal cases. Among them, the median gestation period at birth was 35 WG (range: 22-41 WG) with 
TABLE 1

Characteristics of pregnancy-related listeriosis cases, France, 1999-2011 (mothers n=603, births n=606)

\begin{tabular}{|l|l|l|}
\hline Characteristics & Population & Missing data \\
\hline Age of mothers, in years: mean $( \pm \mathrm{SD})$ & $29.5( \pm 6.1)$ & 10 \\
\hline Type of pregnancy-related listeriosis: $\mathrm{n}(\%)$ & & \\
\hline Foetal loss (miscarriage or stillbirth) & $166(27 \%)$ & 0 \\
\hline Live-born neonatal listeriosis & $351(58 \%)$ & 0 \\
\hline Maternal infection with ongoing pregnancy & $89(15 \%)$ & 0 \\
\hline Gestational age: median (range) & $32(5-41)$ & 21 \\
\hline Completed food questionnaire: $\mathrm{n}(\%)$ & $509(84 \%)$ & 0 \\
\hline At least one not recommended product consumed: $\mathrm{n}(\%)$ & $405(80 \%)$ & 0 \\
\hline Number of different types of not recommended food products consumed: median (range) & $3(1-14)$ & 0 \\
\hline Type of not recommended products consumed: $\mathrm{n}(\%)$ & & \\
\hline Pâté & $256(51 \%)$ & 0 \\
\hline Dried sausage & $208(41 \%)$ & 0 \\
\hline Smoked salmon & $165(33 \%)$ \\
\hline Unpasteurised cheeses & $101(20 \%)$ & 0 \\
\hline
\end{tabular}

$95 \%(n=314)$ diagnosed less than 48 hours after birth. There were 109 (33\%) confirmed invasive cases and among them 14 (13\%) cases had L. monocytogenes culture-positive CSF. Among the 195 probable cases, there were 132 (68\%) cases with maternal infection (placenta or maternal blood culture-positive) and 63 (32\%) cases with no evidence of maternal infection but L. monocytogenes isolated from the neonate's gastric aspirate. There were only $25(8 \%)$ possible cases with L. monocytogenes isolated exclusively from the neonate's surface swabs. Twenty-six (8\%) early neonatal cases died. The median duration of life before death was 1 day (range: 0-24 days). Neonatal case fatality fell with gestational age, from $33 \%$ in highly preterm births ( $<28 W G)$ to $2 \%$ in infants born at term $(p=0.05)$.

Among the 18 cases of late neonatal listeriosis, the median gestation period was 39 WG (range: $35-41$ WG). It was significantly longer than the gestation period of the early neonatal listeriosis cases (p<0.001). All of them had L. monocytogenes culture-positive CSF. Three clusters of nosocomial infection by possible crossinfection between pairs of neonates born at the same time in the same hospital were identified. In all three clusters, the first baby had an early onset listeriosis and the second baby presented, several days later, a late neonatal listeriosis. In each pair the L. monocytogenes strains belonged to the same PCR serogroup and exhibited indistinguishable PFGE patterns. None of the late neonatal cases died. Information on treatment was not available to the authors.

Microbiological analyses

L. monocytogenes strains were sent to NLRC for 589 cases of pregnancy-related listeriosis: PCR serogroup IVB was predominant $(n=362 ; 61 \%)$, followed by IIB $(n=111 ; 19 \%)$, IIA ( $n=109 ; 19 \%)$, and IIC $(n=7 ; 1 \%)$. In the population with non-pregnancy-related listeriosis, the distribution of PCR serogroups was IVB $(n=1,487 ; 46 \%)$, followed by IIA $(n=810 ; 25 \%)$, IIC $(n=521 ; 16 \%)$ and IIB $(n=443 ; 14 \%)$ which differed significantly from the distribution in the population with pregnancy-related listeriosis ( $p<0.001)$. There was no association between PCR serogroup and fetal loss $(p=0.17)$ or between PCR serogroup and neonatal death $(p=0.08)$. For neonates, the PCR serogroup distribution was similar in cases with L. monocytogenes culture-positive CSF and for cases that were not neuro-invasive $(p=0.43)$. No resistance was observed to any clinically relevant antibiotics recommended for the treatment of listeriosis.

\section{Discussion}

In France, the incidence of pregnancy-related listeriosis decreased markedly from 1986 to 1996. A similar reduction in the incidence of listeriosis was observed in the United States (US) between 1989 and 1993 and coincided with the implementation of industrial, regulatory, and educational measures [24]. Previous analyses have suggested that a substantial part of the decrease in illness due to L. monocytogenes from 1986 to 1996 in France was related to control measures implemented at the food production level [9]. The first Listeria control measures, implemented in France in 1986, targeted manufacturers producing cheese for exportation to the US, since American authorities had imposed a 'zero Listeria' rule on imported cheeses. These control measures were subsequently extended to all cheese producers in France in 1988. In 1992, a large outbreak involving 279 cases throughout France, including 92 pregnancy-related cases, prompted the French Ministry of Health to issue recommendations to pregnant women to avoid certain foods. After this 
Pregnancy-related listeriosis cases by gestational age at diagnosis, France, 1999-2011 (n=585)

\begin{tabular}{|l|c|c|c|c|c|c|c|c|c|}
\hline \multirow{2}{*}{$\begin{array}{l}\text { Gestational age at } \\
\text { diagnosis }\end{array}$} & \multicolumn{3}{|c|}{ All cases } & $\begin{array}{c}\text { Maternal infection with } \\
\text { ongoing pregnancy }\end{array}$ & $\begin{array}{c}\text { Foetal loss } \\
\text { (miscarriage + stillbirth) }\end{array}$ & \multicolumn{3}{c|}{ Live-born neonatal listeriosis } \\
\cline { 2 - 12 } & $\mathrm{n}=585$ & $\%$ & $\mathrm{n}=87$ & $\%$ & $\mathrm{n}=161$ & $\%$ & $\mathrm{n}=337$ & $\%$ \\
\hline <14 WG & 23 & $4 \%$ & 8 & $9 \%$ & 15 & $9 \%$ & 0 & 0 & 0 \\
\hline $14-21$ WG & 92 & $16 \%$ & 17 & $20 \%$ & 75 & $47 \%$ & 0 & 0 & 0 \\
\hline $22-27$ WG & 98 & $17 \%$ & 13 & $15 \%$ & 55 & $34 \%$ & 30 & $9 \%$ & 10 \\
\hline $28-31$ WG & 79 & $14 \%$ & 9 & $10 \%$ & 10 & $6 \%$ & 60 & $18 \%$ & 10 \\
\hline $32-36$ WG & 163 & $28 \%$ & 32 & $37 \%$ & 5 & $3 \%$ & 126 & $37 \%$ & 4 \\
\hline$\geq 37$ WG & 130 & $22 \%$ & 8 & $9 \%$ & 1 & $1 \%$ & 121 & $36 \%$ & 2 \\
\hline
\end{tabular}

WG: weeks of gestation.

outbreak, control measures were extended to include all foods potentially contaminated with L. monocytogenes, and hygiene measures were strengthened throughout the food distribution chain. Between 1992 and 1996 , the proportion of highly contaminated foodstuffs ( $\geq 100$ colony-forming units/g) fell substantially. Between 1994 and 2000, additional measures were implemented, such as systematic withdrawal of contaminated foods from the market and distribution of information leaflets to pregnant women by their physicians. The incidence of pregnancy-related listeriosis in France continued to fall gradually from 1996 to 2006 and has been stable since 2006. The incidence of pregnancy-related listeriosis in England, which was, in 1985, 10 times lower than in France, also decreased substantially over the same period, from 45 cases in 1985 to 15 to 20 cases per year in the early 2000 [ [25].

Over the last two decades, the sensitivity of the surveillance system has increased. Capture-recapture studies estimate that $76 \%$ of laboratory-confirmed cases were ascertained in 1997 [9], before introduction of the mandatory notification in 1998. This proportion was estimated at $87 \%$ in 2001 [13] and at $92 \%$ in 2006 (data not shown). Consequently, the decrease in incidence observed since 1997 is slightly underestimated.

The geographical distribution was not the same for pregnancy-related and other cases. The higher incidence seen in the south-west of France, both for pregnancy-related and other cases, is puzzling. As listeriosis is transmitted by food, this higher incidence could be a consequence of specific eating habits in this region. The food questionnaire highlighted a higher consumption only for a few high-risk products in this region. However, the questionnaire focused on food products that are mostly available throughout the country like pasteurised milk cheeses. Thus, it is possible that certain high-risk products available only in the south-west and not listed in the questionnaire, contributed to this higher incidence. Another hypothesis could be that mothers in the south-west were less aware of dietary preventive measures than in the rest of the country. Indeed, the proportion of women in this region consuming rillettes, a high-risk product specifically targeted by the dietary recommendations, was higher than elsewhere. In France, dietary recommendations in pregnancy target both listeriosis and toxoplasmosis prevention. Interestingly, toxoplasmosis seroprevalence in pregnant women is higher in south-western France than in other regions of the country [26], supporting the hypothesis that mothers in the south-west may be less aware of dietary preventive measures. Furthermore, as women not immunised against toxoplasmosis are screened each month during their pregnancy in order to detect a seroconversion, they have a regular opportunity to receive these recommendations. We hypothesise that toxoplasmosispositive pregnant women are less likely to be informed about dietary prevention measures than toxoplasmosis-negative pregnant women. This hypothesis is supported by the correlation between the regional incidence of pregnancy-related listeriosis and the regional seroprevalence of toxoplasmosis in pregnant women $(r=0.53, p=0.01)[26]$.

Overall, most mothers had consumed several types of foods not recommended during pregnancy. This highlights the need to improve health education of mothers during pregnancy, in particular in certain regions. Regarding the seasonality, there is a time lag between the seasonal peak in pregnancy-related listeriosis cases and the other forms of listeriosis. As has been recently established, the incubation period for pregnancy-related listeriosis (median of 28 days, ranging from 17 days to 67 days), is much longer than the incubation period for other clinical forms of listeriosis [27]. This may explain that, even if the peak in exposure occurs in the same season, the peak in diagnosis of pregnancy-related cases is some weeks later than other cases.

Pregnancy-related listeriosis mostly affects healthy women without additional predisposing conditions $[28,29]$. Indeed, in our study, only $3 \%$ of the mothers had additional predisposing conditions. 
From 1999 to $2010,18 \%$ of reported listeriosis cases occurred in pregnant women or neonates. This proportion was similar in other countries such as the US $(16 \%$, from 2004 to 2007) [30], Germany (15\%, from 2001 to 2005) [31], and England (12\%, from 2001 to 2008) [25]. In our study, $27 \%(n=166)$ of pregnancy-related cases resulted in fetal loss, compared to $20 \%$ in the US (from 2004 to 2007) [30] and 33\% in Denmark (from 1994 to 2005) [5]. The proportion of cases with ongoing pregnancy in our study (15\%) was similar to the proportion reported in Denmark (13\%) [5].

The proportion of preterm births among listeriosis cases is extremely high: $70 \%$ of 408 neonatal listeriosis cases were preterm births, compared with $7 \%$ of the total 14,832 births in a survey carried out in France in 2010 (relative risk (RR): 9.5; 95\% confidence interval (Cl): 8.5-10.8) [22]. The discrepancy is even higher for severely premature births ( $\$ 32 \mathrm{WG}$ ): $38 \%$ of neonatal listeriosis cases vs $2 \%$ of all births in France (RR: 25.7; 95\% Cl: 20.9-31.6), and extremely premature births (22-27 WG): $21 \%$ versus $0.7 \%$ of all births in France (RR: 31.2; 95\% Cl: 23.8-42.6) [22]. The prognosis for fetal survival among pregnancy-related listeriosis improves with an increasing gestation period at diagnosis, in particular after 28 WG. Indeed, $87 \%$ of fetal losses were diagnosed before 28 WG. Compared with the study by Humbert et al on 601 pregnancyrelated listeriosis cases in France between 1970 and 1975 , our study shows that the proportion of preterm birth among live-born neonatal cases has not changed (64\% vs 63\%) [32]. However, the case fatality ratio has fallen dramatically: $33 \%$ in the period from 1970 to 1975 versus $4 \%$ in the period 1999 to 2011 (p<0.001) [32], probably due to the progress in neonatal care. The proportion of stillbirths in preterm infants (22-31 WG) with neonatal listeriosis is higher than in preterm infants of a general population cohort (Epipage study) ( $39 \%$ vs $25 \%$, p<0,001) [33]. In contrast, the case fatality ratio of live-born preterm neonates with listeriosis is similar to the case fatality ratio of the live-born preterm neonates of Epipage ( $22 \%$ vs $20 \%, p=0.22$ ).

The PCR serogroup distribution differed significantly among pregnancy-related listeriosis and non-pregnancy-related listeriosis. Serogroup IVB, which is the most common PCR serogroup in human listeriosis $[5,14,34,35]$, was more frequent than in non-pregnancyrelated listeriosis and serogroup IIB was less frequent.

This study was based on mandatory notifications made by physicians and microbiologists in the context of the French national surveillance programme on listeriosis and therefore has some limitations. As no information on clinical symptoms was available, we considered neonates with L. monocytogenes isolated exclusively from surface swabs as possible listeriosis cases although they may not actually have been infected. Moreover, we have no information on the long-term sequelae in the newborn. The MONALISA study (Multicentric Observational National Analysis of LISteriosis and ListeriA; http://clinicaltrials.gov/show/ NCT01520597), a prospective study on listeriosis, will present detailed clinical, biological and microbiological data of all incident cases of listeriosis in France from the end of November 2009 until 2013, including pregnancy-related cases, and provide extensive information on the prognosis of newborns.

\section{Conclusion}

Pregnancy-related L. monocytogenes infection is a rare but severe infection in pregnancy. The proportion of fetal loss (27\%) and, for neonatal listeriosis, the proportion of preterm birth (64\%) is extremely high. Fortunately, there has been a marked decrease in incidence from 1984 to 2006 related to the implementation of specific $L$. monocytogenes control measures at the food production level. It is important to maintain these measures, which have proven their efficacy. The incidence of pregnancy-related listeriosis was lower in regions where the prevalence of toxoplasmosis was lower, and this may be related to differences in the distributed information about preventing toxoplasmosis and listeriosis. This suggests that promotion of dietary recommendations could contribute to the prevention of listeriosis in pregnancy. As $80 \%$ of mothers reported having eaten high-risk food during pregnancy, fetal loss (13 cases/year) could be reduced by improving awareness of pregnant women, in particular about dietary recommendations.

\section{Acknowledgements}

We are indebted to the clinicians, microbiologists that isolate Listeria from patient samples and employees of the local health departments, to the Institut Pasteur, particularly to Viviane Chenal-Francisque, the Institut de Veille Sanitaire, particularly to Veronique Vaillant, and the Ministry of Health; Ministry of Agriculture and Ministry of Finance who contributed to human listeriosis surveillance in France.

This work was supported by the National Institute of Health which is funded by the French Ministry of Health.

\section{Conflict of interest}

None declared.

\section{Authors' contributions}

Delphine Girard analysed and interpreted data, drafted and revised the manuscript. Alexandre Leclercq performed typing of the Lm strains, and participated in writing the manuscript. Edith Laurent collected and analysed data. Marc Lecuit and Henriette De Valk interpreted data and revised the article for intellectual content. Véronique Goulet conceptualised and designed the study, designed the data collection instruments, interpreted data, participated in writing the article. All authors approved the final manuscript as submitted. 


\section{References}

1. Schwartz B, Ciesielski CA, Broome CV, Gaventa S, Brown GR, Gellin BG, et al. Association of sporadic listeriosis with consumption of uncooked hot dogs and undercooked chicken. Lancet. 1988;2(8614):779-82.

http://dx.doi.org/10.1016/S0140-6736(88)92425-7

2. Mead PS, Slutsker L, Dietz V, McCaig LF, Bresee JS, Shapiro C, et al. Food-related illness and death in the United States. Emerg Infect Dis. 1999;5(5):607-25. http://dx.doi.org/10.3201/eid0505.990502

3. Goulet V, Hebert M, Hedberg C, Laurent E, Vaillant V, De Valk $\mathrm{H}$, et al. Incidence of listeriosis and related mortality among groups at risk of acquiring listeriosis. Clin Infect Dis. 2012;54(5):652-60. http://dx.doi.org/10.1093/cid/cirgo2

4. Doganay M. Listeriosis: clinical presentation. FEMS Immunol Med Microbiol. 2003;35(3):173-5. http://dx.doi.org/10.1016/S0928-8244(02)00467-4

5. Smith B, Kemp M, Ethelberg S, Schiellerup P, Bruun BG, Gerner-Smidt $P$, et al. Listeria monocytogenes: maternalfoetal infections in Denmark 1994-2005. Scand J Infect Dis. 2009;41(1):21-5 http://dx.doi.org/10.1080/00365540802468094

6. Rocourt J. Listériose humaine: aspects cliniques et épidémiologiques: Rôle de l'alimentation. [Listeriosis human clinical and epidemiological aspects: Role of alimentation]. Le Cahier Technique du Biologiste. 1988;179:29-45. French.

7. Nelson KE, Warren D, Tomasi AM, Raju TN, Vidyasagar D. Transmission of neonatal listeriosis in a delivery room. Am J Dis Child. 1985;139(9):903-5.

8. Rocourt J, Seeliger HP. La listériose: une infection hospitalière? [Listeriosis: a hospital infection?]. Med Mal Infect. 1985;15:7215. French.

http://dx.doi.org/10.1016/S0399-077X(85)80320-6

9. Goulet V, de Valk H, Pierre O, Stainer F, Rocourt J, Vaillant V, et al. Effect of prevention measures on incidence of human listeriosis, France, 1987-1997. Emerg Infect Dis. 2001;7(6):9839. http://dx.doi.org/10.3201/eido706.010610

10. Démographie - Nombre de naissances vivantes - France hors Mayotte. [Demographics - Number of live births - France off Mayotte]. Paris: Institut national de la statistique et des etudes économiques (Insee). [Accessed 18 Jan 2013]. French. Available from: http://www.insee.fr/fr/bases-de-donnees/bsweb/serie. asp?idbank $=001641601$

11. Goulet V, Brohier S. [Listeriosis in France in 1986: census made by hospital laboratories]. Pathol Biol (Paris). 1989;37(3):20611. French.

12. Jacquet C, Martin P, Rocourt J Listériose humaine en France en 2001. Données du Centre National de Référence des Listeria. [Data from the National Reference Center for Listeria.]. Feuillets de Biologie. 2002;245:84-6. French.

13. Goulet V, Jacquet C, Martin P, Vaillant V, Laurent E, De Valk H. La surveillance de la listériose en France en 2001. [Surveillance of listeriosis in France in 2001]. Bull Epidemiol Hebd. 2004;9:33-4. French. Available from: http://www.invs.sante.fr/ beh/2004/09/beh_09_2004.pdf

14. Goulet V, Hedberg C, Le Monnier A, de Valk H. Increasing incidence of listeriosis in France and other European countries. Emerg Infect Dis. 2008;14(5):734-40. http://dx.doi.org/10.3201/eid1405.071395

15. Bille J, Catimel B, Bannerman E, Jacquet C, Yersin MN, Caniaux I, et al. API Listeria, a new and promising one-day system to identify Listeria isolates. Appl Environ Microbiol. 1992;58(6):1857-60.

16. Seeliger HP, Höhne K. Serotyping of Listeria monocytogenes and related species. Methods Microbiol. 1979;13:31-49. http://dx.doi.org/10.1016/S0580-9517(08)70372-6

17. Doumith M, Buchrieser C, Glaser P, Jacquet C, Martin P. Differentiation of the major Listeria monocytogenes serovars by multiplex PCR. J Clin Microbiol. 2004;42(8):3819-22. http://dx.doi.org/10.1128/JCM.42.8.3819-3822.2004

18. Graves LM, Swaminathan B. PulseNet standardized protocol for subtyping Listeria monocytogenes by macrorestriction and pulsed-field gel electrophoresis. Int J Food Microbiol. 2001;65(1-2):55-62. http://dx.doi.org/10.1016/S0168-1605(00)00501-8

19. European Committee on Antimicrobial Susceptibility Testing (EUCAST). Breakpoint tables for interpretation of MICs and zone diameters, v. 3.1, p 68. Växiö: EUCAST; 2013. Available from: http://www.eucast.org/clinical_breakpoints/

20. Clinical and Laboratory Standards Institute (CLSI). Approved guideline M45-A2. In: Methods for antimicrobial dilution and disk susceptibility testing of infrequently isolated or fastidious bacteria. 2nd ed. Wayne: CLSI; 2010.
21. Clinical and Laboratory Standards Institute (CLSI). Approved standard M2-A9. In: Performance standards for antimicrobial disk susceptibility tests. 11th ed. Wayne: CLSI; 2012.

22. Blondel B, Lelong N, Kermarrec M, Goffinet F. Trends in perinatal health in France from 1995 to 2010. Results from the French National Perinatal Surveys. J Gynecol Obstet Biol Reprod (Paris). 2012;41(4):e1-e15. http://dx.doi.org/10.1016/j.jgyn.2012.04.014

23. Janakiraman V. Listeriosis in pregnancy: diagnosis, treatment, and prevention. Rev Obstet Gynecol. 2008;1(4):179-85.

24. Tappero JW, Schuchat A, Deaver KA, Mascola L, Wenger JD. Reduction in the incidence of human listeriosis in the United States. Effectiveness of prevention efforts? The Listeriosis Study Group. JAMA. 1995;273(14):1118-22. http://dx.doi.org/10.1001/jama.1995.03520380054035 http://dx.doi.org/10.1001/jama.273.14.1118

25. Mook P, Grant KA, Little CL, Kafatos G, Gillespie IA. Emergence of pregnancy-related listeriosis amongst ethnic minorities in England and Wales. Euro Surveill. 2010;15(27): pii=19610.

26. Berger F, Goulet V, Le Strat Y, Desenclos IC. Toxoplasmosis among pregnant women in France: risk factors and change of prevalence between 1995 and 2003. Rev Epidemiol Sante Publique. 2009;57(4):241-8. http://dx.doi.org/10.1016/j.respe.2009.03.006

27. Goulet V, King LA, Vaillant V, de Valk H. What is the incubation period for listeriosis? BMC Infect Dis. 2013;11. doi: 10.1186/1471-2334-13-11. http://dx.doi.org/10.1186/1471-2334-13-11

28. Mylonakis E, Paliou M, Hohmann EL, Calderwood SB, Wing EJ. Listeriosis during pregnancy: a case series and review of 222 cases. Medicine (Baltimore). 2002;81(4):260-9. http://dx.doi.org/10.1097/00005792-200207000-00002

29. Siegman-Igra Y, Levin R, Weinberger M, Golan Y, Schwartz D, Samra Z, et al. Listeria monocytogenes infection in Israel and review of cases worldwide. Emerg Infect Dis. 2002;8(3):305-10. http://dx.doi.org/10.3201/eido803.010195

30. Jackson KA, Iwamoto M, Swerdlow D. Pregnancy-associated listeriosis. Epidemiol Infect. 2010;138(10):1503-9. http://dx.doi.org/10.1017/So950268810000294

31. Koch J, Stark K. Significant increase of listeriosis in Germany-epidemiological patterns 2001-2005. Euro Surveill. 2006;11(6): pii=631.

32. Humbert G, Duval C, Fessard C, Meunier M, Ledoux A. Human listeriosis in France to day : a study of 824 cases Part II : pregnancy and neo-natal listeriosis. Lyon Medical. 1977;237(6):455-68.

33. Larroque B, Bréart G, Kaminski M, Dehan M, André M, Burguet $A$, et al. Survival of very preterm infants: Epipage, a population based cohort study. Arch Dis Child Fetal Neonatal Ed. 2004;89(2):F139-44. http://dx.doi.org/10.1136/adc.2002.020396

34. Doorduyn Y, de Jager CM, van der Zwaluw WK, Wannet WJ, van der Ende A, Spanjaard L, et al. Invasive Listeria monocytogenes infections in the Netherlands, 1995-2003. Eur J Clin Microbiol Infect Dis. 2006;25(7):433-42. http://dx.doi.org/10.1007/s10096-006-0157-4

35. Hof H. History and epidemiology of listeriosis. FEMS Immunol Med Microbiol. 2003;35(3):199-202 http://dx.doi.org/10.1016/So928-8244(02)00471-6 